\title{
TOWARDS A JURISPRUDENCE OF SUSTAINABILITY IN A TIME OF TRANSITION
}

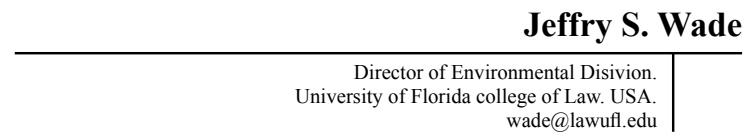

\begin{abstract}
In recent decades, an increasing number of disturbing trends have prompted many scientists and policy analysts to suggest that, as a species, we may be on the verge of a major transition or turning point. Persistent negative trends in resource availability, biodiversity, environmental quality and human well-being indicate that the current global development model may be damaging Earth's essential systems and processes beyond recovery. Environmental law, as it exists in most countries, has not succeeded in controlling the impacts and effects of this development model. A jurisprudence of sustainability is necessary, based on a set of principles that will ensure a more proactive, scientifically-based, integrated, communal and transparent approach to development regulation.
\end{abstract}

Keywords: Sustainability. Environmental Law. Natural resources. Time. Transition. 


\section{INTRODUCTION}

Over the millennia of human existence, mankind has experienced several major turning points involving technology and culture. Our transitions into the Age of Fire, the Stone Age, the Bronze Age, the Industrial Revolution and the Atomic Age represent only a few of these turning points, but each has had profound effects on human cultures and economies, the ways we live our lives and the ways in which we interact with each other.

In recent decades, an increasing number of disturbing trends have prompted many scientists and policy analysts to suggest that, as a species, we may be on the verge of another major transition or turning point, one that could be more difficult than those that have preceded it, and perhaps just as inevitable. Many scientists have informally begun to characterize the current geologic epoch as the Anthropocene, one in which humans, and their activities, have become the dominant planetary force ${ }^{1}$. The accompanying transition being proposed is not directly driven by technology but by population growth and the effects of a development model that has failed to recognize the limits and boundaries associated with life on a finite planet.

\section{A TIME OF TRANSITION}

Despite widespread adoption of environmental laws, resource management programs and efforts at creating equitable societies around the globe, most environmental and many sociocultural indicators have been moving in the wrong direction for decades ${ }^{2}$. Human population is expanding at an exponential rate, overconsumption of natural resources is rampant, and though "quality of life" indices were at one point increasing, they are now falling in many parts of the world ${ }^{3}$. A large number of wildlife populations and habitats, as well as overall biodiversity, are declining,

\footnotetext{
${ }^{1}$ See, eg., Zalasiewicz et al. "The New World of the Anthropocene", 44 Environmental Science \& Technology 2228 (2010) (<http://pubs.acs.org/doi/pdf/10.1021/es903118j>).

2 "Key Environmental Indicators: Tracking Progress Towards Environmental Sustainability", Chapt. 4 In Unep Yearbook 2012, New York (<http://www.UNEP.org/Yearbook/2012/>); The Millennium Development Goals Report 2012, UN New York (2012) (<http://Mdgs.Un.Org/Unsd/Mdg/Resources/ Static/Products/Progress2012/English2012.Pdf $>$ ).

${ }^{3}$ The Millennium Development Goals Report 2012, UN New York (2012) (<http://Mdgs.Un.Org/ Unsd/Mdg/Resources/Static/Products/Progress2012/English2012.Pdf $>$ ).
} 
some very rapidly ${ }^{4}$. The large majority of marine fish are under great stress as a result of overfishing, loss of mangrove habitats and the tremendous amounts of pollution being discharged into coastal waters used as breeding and nursery areas ${ }^{5}$. It is expected that ocean acidification and warming as a result of the continuing massive use of fossil fuels will have even greater negative impacts on marine organisms ${ }^{6}$.

With a projected global population of 9 billion by 2050 , there are also very real concerns about food security. Agricultural lands are being exhausted at record rates because of industrial production methods and massive overuse of petrochemical fertilizers, pesticides and fungicides ${ }^{7}$. Sources of water for domestic use, agriculture and industry are being depleted and polluted at record rates in many parts of the world ${ }^{8}$. Virgin forests are being cut at near-record rates for timber, and to create new agricultural land 9 .

Globally, air quality is generally falling, while the rates of fossil fuel use and release of greenhouse gases continue to rise ${ }^{10}$. Oceans are warming, expanding and acidifying, killing coastal wetlands and vital coral reef ecosystems ${ }^{11}$. We are already experiencing - and will continue to experience for many decades - devastating weather events with profound effects on human lives and property, agriculture, natural resources and wildlife species around the world.

Some indicators are more positive in some parts of the world,

\footnotetext{
${ }^{4}$ Butchart, Walpole, Collen, et al., "Global Biodiversity: Indicators of Recent Declines", 328 Science 1164 (May 2010).

5 "General Situation of World Fish Stocks", United Nations Food and Agriculture Organization, Rome (undated) (<http://www.fao.org/newsroom/common/ecg/1000505/en/stocks.pdf $>$ ); "Review of the State of World Marine Fishery Resources", FAO Fisheries and Aquaculture Technical Paper 569, United Nations Food and Agriculture Organization, Rome (2011).

${ }^{6}$ Kroeker, Kordas, Crim and Singh, "Meta-Analysis Reveals Negative Yet Variable Effects of Ocean Acidification on Marine Organisms", 13 Ecology Letters 1419 (2010).

7 "The State of the World's Land and Water Resources for Food and Agriculture: Managing Systems at Risk", United Nations Food and Agriculture Organization, Rome (2011).

${ }^{8}$ Hoekstra, Mekonnen, Chapagain, Mathews and Richter, "Global Monthly Water Scarcity: Blue Water Footprints versus Blue Water Availability", PLoS ONE 7(2) (February 2012) ( $<$ http://www.plosone. org/article/info\%3Adoi\%2F10.1371\%2Fjournal.pone.0032688>).

${ }^{9}$ Kissinger, Herold and De Sy, "Drivers of Deforestation and Forest Degradation: A Synthesis Report for REDD + Policymakers", Lexeme Consulting, Vancouver Canada (August 2012) $(<\mathrm{https}: / / \mathrm{www}$. gov.uk/government/uploads/system/uploads/attachment_data/file/65505/6316-drivers-deforestationreport.pdf $>$ ).

${ }^{10}$ Olivier, Janssens-Maenhout and Peters, "Trends in Global CO2 Emissions: 2012 Report”, PBL Netherlands Environmental Assessment Agency, The Hague/Bilthoven (2012).

${ }^{11}$ Halpern, Walbridge, Selkoe et al. "A Global Map of Human Impact on Marine Ecosystems", 319 Science 948 (February 2008).
} 
but overall, the long-term global trends are deeply troubling. What they suggest is that the basic structures of our economies and approaches to development are flawed and do not respect the realities of life on a finite planet. They suggest that the existing system of environmental law is lacking. They suggest the need for a transition to a more truly sustainable development model, and a fundamental restructuring of our relationship to the planet and to each other. This transition will require an intellectual and emotional evolution, from development based on exploitation of the natural world and other humans (often called a "frontier mentality") ${ }^{12}$, to development based on restoration, maintenance, respect and cooperation (what might be called an "inhabiting mentality").

I only offer these labels as possible characterizations. They represent the difference in consciousness between, on the one hand, people who come to a new, unspoiled country or frontier with the intent to simply control and exploit it, and on the other hand, people who live within ("inhabit") a landscape, respecting inherent limits on the number of resources that can be used and on the amounts of waste that can be naturally assimilated. People who truly inhabit a region have a fundamentally different relationship to other species, to natural resources and to each other than those who live with a frontier mentality. The transition I am speaking of will involve a complete cultural evolution, moving from economies, laws and institutions based on the frontier mentality to those based on an inhabiting mentality.

How this transition could occur is difficult to project. It's possible to imagine that a confluence of overwhelming weather events, social upheavals, economic crises and severe resource depletion might catalyze a rapid expansion of consciousness which would drive a reconceptualization of development models, economic institutions, legal structures and social relations. It's also possible that slow, incremental changes will drive the process. Regardless of the means by which the transition occurs, I would suggest that there is a clear role for proactive thinking which anticipates this transition and attempts to facilitate it by making more significant structural changes as soon as possible. It's important to remember that governance structures are designed by humans and can be modified by humans in order to respond to new conditions. None of the existing systems are "carved in stone". Judges, attorneys, professors and students can contribute by thinking

\footnotetext{
${ }^{12}$ Sakamoto, H., "Towards a New Global 'Bioethics”, 3 Bioethics 191 (1999) (https://notendur.hi.is/ $\sim$ ssigma/PDF\%20files/Sakamoto.pdf).
} 
now about the broad outlines of a new jurisprudence of sustainability.

There is an initial question concerning the scope of the effort which will be necessary. In the U.S., during the debates surrounding the Civil Rights Act of 1964, ${ }^{13}$ a famously conservative Senator hypocritically refused to vote for the act, arguing that "You cannot legislate morality"14.

The Act was adopted, and proved to be a very valuable tool in the struggle for equal rights. Given the uncertainties surrounding the principles, goals and methods for achieving true sustainability, it might be tempting to take the same position with regards to the current transition, that we cannot legislate sustainability. I would agree that laws and regulations alone will not be sufficient. It will be necessary to mobilize the entire set of governance tools in order to incorporate the values and practices of sustainability into our societies. This would include, but is not limited to, media efforts, educational institutions, legal and social structures, religious institutions, governmental information programs and, where possible, the efforts of businesses and corporations.

But I would also argue that, if the transition is apparent and if it is necessary, both of which seem true, then we as legal professionals are obligated to make our contribution, in order to conceive a new legal structure which helps to define, support and implement the transition. It may begin with less than perfect understanding of its goals and methods, but it should begin, with the understanding that larger structural reform is necessary. In most cases, attempting to simply adjust and modify the existing structure will not be sufficient.

The industrial revolution and the development model that we now have were in place long before environmental law began to exert any influence over the process. Modern environmental law was, and for the most part still is, a reaction to that model. It tries to mitigate environmental problems more or less "after the fact". It takes the viability of the industrial "frontier" development model as an essential condition, then attempts to manage the negative environmental consequences, using command and control regulations, or market-based pollution trading, or hybrid approaches combining economic incentives and regulations, or any of the other standard tools. But the sum of these types of protections is not remotely sufficient to counteract the cumulative and growing damage inflicted every day, in

\footnotetext{
${ }^{13}$ Civil Rights Act of 1964 (Pub.L. 88-352, 78 Stat. 241, July 2, 1964).

${ }^{14}$ Bromley, N., "The 'Lunatic Fringe' - Barry Goldwater and the Conservative Revolution of the 1960s", Colby College Theses, Paper 595 (2010) (<http://preview.tinyurl.com/d8umnye $>$ ).
} 
every part of the world by the current development model.

Environmental law presumes that our existing approach to conceiving, designing and implementing development projects is fundamentally sound and that what is necessary are modifications and adjustments to the legal controls in order to improve or even perfect the system. But as should be obvious, if truly sustainable development is the goal, the current approach to environmental law has shown that it is probably not up to the task ${ }^{15}$.

Our existing system of development management, including environmental law, has little or no role in the early design stages of a development proposal. It is not given a proactive, creative function in the process, but is usually forced to react to the proposal after it has been conceived, designed and submitted for approval. In almost all cases, the only people involved in the creative process are economic and political elites, whose values and goals may be very different than those which are necessary to move us towards a sustainable society. This "top-down" approach to environmental law is one of the problems which must be addressed in future systems of development management ${ }^{16}$.

Environmental law is also fragmented; different legislative enactments address different aspects of a development proposal. In many cases, these laws are applied and enforced by separate agencies or authorities ${ }^{17}$. The agencies rarely collaborate or confer on the ways in which the conditions in a permit, or the actual development proposal itself, might be structured in order to achieve long-term environmental stability in more than one medium. There are also the problems of bureaucratic conflict, excessive paperwork and the diversion of time and energy from effective regulation.

Environmental law is subject to questionable judicial interpretation and politicization. One example is the U.S. National Environmental Policy Act, which contains language strongly promoting the goals of sustainability. It has the potential to require federal agencies

\footnotetext{
${ }^{15}$ Adler, J., "Conservative Principles for Environmental Reform", Case Research Paper Series in Legal Studies, Working Paper 2013-9, Case Western Reserve University School of Law (March, 2013). See also, Rosenbaum, K. "The Challenge of Achieving Sustainable Development Through Law", 27 Environmental Law Reporter 10455 (1997).

${ }^{16}$ Dellinger, M., “An Unstoppable Tide: Creating Environmental and Human Rights Law from the Bottom Up", (forthcoming), Oregon Review Of International Law (2013).

${ }^{17}$ Rosenbaum, K. "The Challenge of Achieving Sustainable Development Through Law", 27 Environmental Law Reporter 10455 (1997).
} 
which are contemplating major projects to choose the version of that project that is most environmentally sound ${ }^{18}$. However, early in its life, the Act was judicially interpreted to require only a process of environmental assessment, leaving the final decision to the discretion of the agency ${ }^{19}$. After going through the required assessment procedures, the agency can now essentially take any reasonable course of action; it is not required to pursue the most environmentally preferred option ${ }^{20}$. The problem of judicial interpretation is partially related to the construction of the legislation itself - how clear and direct it is in what it requires - but it is also related to political will, the education and training of judges, and, at least in the U.S., avoiding overtly political judicial appointments.

If these are some of the weaknesses of existing environmental law, the question becomes: how can we begin to conceptualize an effective jurisprudence of sustainability? Though the creation and implementation of this jurisprudence will require years of effort, it might be helpful to begin by formulating some general principles or guidelines. I can suggest at least a partial list. This is not an exhaustive approach, but can provide an initial grounding for the types of concerns that should be addressed.

Natural Jurisdictions: It is vitally important to make jurisdictional boundaries for development management congruent with ecoregional boundaries or hydrogeographic boundaries. If the functioning of the natural world is the focus of our efforts - if we recognize that our well-being is closely associated with environmental health and that the effects of our development decisions will be most deeply felt within natural ecoregions - then our development decisions must take place within boundaries that correspond to natural processes. One example is represented by the state of Florida (U.S.), in which the water management system is based on jurisdictional boundaries that follow hydrogeographic boundaries ${ }^{21}$. It would be optimal to make development planning and decision-making dependent on similar boundaries. Given the political inclinations of our

\footnotetext{
${ }^{18}$ Weiner, K., "Accountability for Mitigation Through Procedural Review: The NEPA Jurisprudence of Judge Betty B. Fletcher, A Trustee of the Environment and Woman of Substance", 85 Washington L. Rev. 45 (2010), at 49.

${ }^{19}$ Calvert Cliffs' Coordinated Committee v. Atomic Energy Commission, 449 F. 2d 1109, 1114 (D.C. Cir. 1971), cert denied, 404 U.S. 942 (1972).

${ }^{20} \mathrm{Id}$., at 1112 .

${ }^{21}$ Olexa, Borisova and Broome, "Handbook of Florida Water Regulation: Water Management Districts". EDIS document FE594, Florida Cooperative Extension Service, Institute of Food and Agricultural Sciences, University of Florida, Gainesville, FL. (June 2011) $(<\mathrm{http}: / /$ edis.ifas.ufl.edu/pdffiles/FE/FE59400.pdf >).
} 
species, this will be a difficult adjustment, but I'm being visionary here, so I've included it as a principle. Generally, the broader the jurisdiction of the development review authority, the greater is the opportunity to make decisions that are congruent with natural boundaries and that will maintain the functioning of the relevant region.

Scientifically-Based: This is a related principle that respects the critical role that valid, peer-reviewed science must play in the decisionmaking process. Any effort to evaluate the environmental impact of a development proposal, as well as efforts to mitigate that impact, must be largely based on validly derived data and research, not on decisionmakers' intuitions or unfounded guesses. Aclassic example is occurring in the United States. Despite overwhelming amounts of peer-reviewed scientific research validating the reality of anthropogenic global warming, the U.S. Congress, as a body, has refused to take action, based primarily on the abilities of a small minority of industry-supported legislators to block effective action in order to maintain the disastrous status quo position. Environmental impact assessment also remains as an important tool, but the scientific research analyzing a development proposal should have priority in determining if that proposal meets the standards required by the applicable legislation ${ }^{22}$.

Proactive: Any effort to create a truly sustainable approach to human development must be more active and less reactive concerning the ways in which development is conceived and implemented. It must be present as a guiding force from the outset. Detailed community plans, regional plans and resource management plans all have a role in this process, but they must be given something close to legally binding authority. If not, they can be changed or ignored by developers and politicians. Within this framework, social, environmental and economic authorities must be given a creative role in the shaping of development proposals.

Integrated: The development management framework must be integrated and coordinated in a way that reflects the complex environmental consequences of most development proposals. Laws which control impacts to different aspects of the environment should be conceived as interrelated frameworks. The institutions responsible for the review of proposals should also be conceived as interconnected and should be legislatively required to engage in full consultation on the merits of each

\footnotetext{
${ }^{22}$ See, eg., Flournoy, Feinberg, Giblin, Halter and Storz, "The Future of Environmental Protection: The Case for a National Environmental Legacy Act," Center For Progressive Reform, White Paper No. 1002 (January 2010) (<http://www.progressivereform.org/articles/NELA_1002.pdf $>$ ).
} 
proposal. Where possible, a single agency might be given responsibility for reviewing as many environmental criteria as possible. If there are concerns that a single agency might be subject to institutional stasis or prejudiced reviews of development proposals, then the combination of agencies which are responsible for implementing the various laws must be required to coordinate their review processes.

Communal: The law of property rights must be carefully addressed, in order to prevent a cultish emphasis on a property owner's perceived right to do whatever he wants to do with his land. What seems to have been lost over the decades is a sense of "property responsibilities". The essential idea is that a jurisprudence of sustainability must recognize community-based environmental and social goals and must shape the law of property rights to recalibrate the balance between individual and community rights ${ }^{23}$. I also believe that corporate law, at least as structured in the U.S., must be radically reformed. Over the years, a series of court decisions have given corporations in the U.S. levels of power and influence that can easily subvert legislative efforts to create sustainable societies ${ }^{24}$. Corporate law holds that publicly owned corporations are legally required to prioritize profits for their shareholders. Failing this duty can leave directors and officers open to being sued by shareholders. In efforts to fulfill the obligation, many corporations have taken actions that are socially and environmentally unsupportable. The nature of this element of corporate law must be revisited and reformed in order to force corporations into more sustainable products and actions ${ }^{25}$.

Participatory: If a truly human-scaled, sustainable approach is desired, the review of development plans and specific proposals must include the participation of many representatives of a society ${ }^{26}$. Participatory processes are becoming more widespread, but it's fairly common for economic and political elites to essentially pre-determine how a proposal should be reviewed and analyzed. Participation and input from civil society is accepted in procedurally accurate, pro forma public meetings, but in

\footnotetext{
${ }^{23}$ See, Doremus, H., "Takings and Transitions", 19 Journal Of Land Use \& Environmental Law 1 (Fall 2003) (<http://www.law.fsu.edu/journals/landuse/vol19_1/doremus.pdf $>$ ).

${ }^{24}$ Eg., Citizens United v. Federal Election Commission, 558 U.S. 310 (2010); Trustees of Dartmouth College v. Woodward, 17 U.S. 518 (1819).

${ }^{25}$ See generally, Morgera, Coporate Accountability In International Environmental Law, Oxford Scholarship Online (May 2009).

${ }^{26}$ Bulkeley and Mol, "Participation and Environmental Governance: Consensus, Ambivalence and Debate", 12 Environmental Values 143 (2003).
} 
most cases, they have little effect on the decision-making process.

The participatory principle requires that participants receive accurate data concerning the development proposal and its impacts, as well as potential alternatives. Where necessary, technical assistance should be provided to participants in order to interpret and summarize the data for those who may not have the technical background to fully understand it. This knowledge must be provided in a timely manner, so that participants have sufficient time to consider the data and proposals before the participatory meeting. And the information and perspectives elicited from public participants must have true weight in the decision-making process.

Transparent: Review of proposals and decision-making about development must take place in open, well-publicized public forums. Any communication between decisionmakers can only take place in these forums, and all records and documents concerning the process are openly and easily available to anyone who requests them ${ }^{27}$. The internet can serve as a valuable tool for making these meetings, records and decisions available to a wide audience, thus increasing the potential for public awareness and participation.

\section{CONCLUSION}

The process of first understanding the scope of the necessary transition, then actively working towards its implementation will be monumental. I propose these principles as preliminary and very broad guidelines for creating a jurisprudence of sustainability - one that supports and facilitates the transition to a realistic development model which respects people, other species and the natural limits of life on a finite planet. The full realization of this jurisprudence will require additional intellectual effort to complete the list of operational principles, to create an outline of the goals and norms flowing from these principles, and to more deeply explore creative methods for incorporating them into our legal and procedural structures. I invite you all to take part in this vitally important effort.

\footnotetext{
27 “Transparency in Government Decision-making”. in OECD Factbook 2011-2012: Economic, Environmental and Social Statistics, OECD Publishing (2011) (<http://dx.doi.org/10.1787/factbook-201195-en>).
} 


\section{REFERENCES}

Adler, J., "Conservative Principles for Environmental Reform", Case Research Paper Series in Legal Studies, Working Paper 2013-9, Case Western Reserve University School of Law (March, 2013). See also, Rosenbaum, K. "The Challenge of Achieving Sustainable Development Through Law”, 27 Environmental Law Reporter 10455 (1997).

Bromley, N., "The 'Lunatic Fringe' - Barry Goldwater and the Conservative Revolution of the 1960s", Colby College Theses, Paper 595 (2010) (<http:// preview.tinyurl.com/d8umnye >).

Butchart, Walpole, Collen, et al., "Global Biodiversity: Indicators of Recent Declines”, 328 Science 1164 (May 2010).

Dellinger, M., “An Unstoppable Tide: Creating Environmental and Human Rights Law from the Bottom Up", (forthcoming), Oregon Review Of International Law (2013).

Halpern, Walbridge, Selkoe et al. "A Global Map of Human Impact on Marine Ecosystems”, 319 Science 948 (February 2008).

Hoekstra, Mekonnen, Chapagain, Mathews and Richter, "Global Monthly Water Scarcity: Blue Water Footprints versus Blue Water Availability", PLoS ONE 7(2) (February 2012) (<http://www.plosone.org/article/info\%3 Adoi\%2F10.1371\%2Fjournal.pone.0032688>).

Key Environmental Indicators: Tracking Progress Towards Environmental Sustainability", Chapt. 4 In: Unep Yearbook 2012, New York $(<\mathrm{http}: / /$ www.UNEP.org/Yearbook/2012/>).

Kissinger, Herold and De Sy, "Drivers of Deforestation and Forest Degradation: A Synthesis Report for REDD + Policymakers", Lexeme Consulting, Vancouver Canada (August 2012) (<https://www.gov.uk/ government/uploads/system/uploads/attachment_data/file/65505/6316drivers-deforestation-report.pdf $>$ ).

Kroeker, Kordas, Crim and Singh, "Meta-Analysis Reveals Negative Yet Variable Effects of Ocean Acidification on Marine Organisms", 13 Ecology Letters 1419 (2010).

Olexa, Borisova and Broome, "Handbook of Florida Water Regulation: 
Water Management Districts". EDIS document FE594, Florida Cooperative Extension Service, Institute of Food and Agricultural Sciences, University of Florida, Gainesville, FL. (June 2011) (<http://edis.ifas.ufl.edu/pdffiles/ FE/FE59400.pdf $>$ ).

Olivier, Janssens-Maenhout and Peters, "Trends in Global CO2 Emissions: 2012 Report”, PBL Netherlands Environmental Assessment Agency, The Hague/Bilthoven (2012).

Rosenbaum, K. "The Challenge of Achieving Sustainable Development Through Law", 27 Environmental Law Reporter 10455 (1997).

Sakamoto, H., "Towards a New Global 'Bioethics", 3 Bioethics 191 (1999) $(<$ https://notendur.hi.is/ ssigma/PDF\%20files/Sakamoto.pdf $>$ ).

See, eg., Flournoy, Feinberg, Giblin, Halter and Storz, "The Future of Environmental Protection: The Case for a National Environmental Legacy Act," Center For Progressive Reform, White Paper No. 1002 (January 2010) (<http://www.progressivereform.org/articles/NELA_1002.pdf $>$ ).

See, eg., Zalasiewicz et al. "The New World of the Anthropocene", 44 Environmental Science \& Technology 2228 (2010) (<http://pubs.acs.org/ doi/pdf/10.1021/es903118j>).

Weiner, K., "Accountability for Mitigation Through Procedural Review: The NEPA Jurisprudence of Judge Betty B. Fletcher, A Trustee of the Environment and Woman of Substance”, 85 Washington L. Rev. 45 (2010), at 49 .

The Millennium Development Goals Report 2012, UN New York (2012) (<http://Mdgs.Un.Org/Unsd/Mdg/Resources/Static/Products/ Progress2012/English2012.Pdf $>$ ). 